\title{
Utilization of Services Related to Safe Motherhood among the Tribal Population of East Khasi Hills (Meghalaya): An Overview
}

\author{
Roumi Deb \\ Amity Institute of Biotechnology, Amity University, Sector-125, Express Highway, Noida
}

KEYWORDS Antenatal care (ANC); public health centre (PHC); community health centre (CHC), focus group discussion (FGD); East Khasi Hills, Meghalaya

\begin{abstract}
In the present paper an attempt has been made to understand the utilization for safe motherhood, particularly, the antenatal care (ANC) among the Khasi Tribes of Meghalaya, India. From this study it was found that antenatal care situation is quite discouraging in this population in the district. Though more than eighty percent received their antenatal check up but most of them received their first antenatal check in the fifth month of their pregnancy. Further, various socio-economic and cultural factors are influencing the acceptance of antenatal care in this community.
\end{abstract}

\section{INTRODUCTION}

The concept of healthy mother and healthy baby is an important aspect of reproductive health care programme. In a developing country like India, poverty, illiteracy and multiple pregnancies take their toll of mother's health and that of the infant. Building national capacity in planning, implementing and monitoring sexual and reproductive health programs is a major challenge in Asian and African countries (Frontiers in Reproductive Health Program).

Due to multidimensional factors, safe motherhood is still a dream for much of India particularly for its rural and tribal population. The goal of safe motherhood aims at maintaining the good health of the mother during pregnancy, which will enable her to produce healthy, normal infant and to remain herself healthy (Bourn, 1972). Against, that backdrop, maternal health receives greater attention after the safe motherhood initiative was launched at international conference held in Nairobi in 1987 (Malher, 1987). Antenatal care is a pivotal factor for the safe motherhood. The primary aim of antenatal care is to achieve healthy mother and a healthy baby at the end of a pregnancy. Mothers who had not received good quality antenatal care were found to be more at risk of having low birth weight babies (Nair et al., 2000) and there is clear association between infant mortality rate and lack of or poor quality antenatal care (Chandrashkehar et al., 1998). Ideally, this should begin soon after conception and continue through out the pregnancy (Park and Park, 1991). However, antenatal care has a number of objectives, which have greater intention to promote, protect and maintain the heath of the pregnant mother. In Indian context, the utilization of antennal care varies across the region and ethnic groups. On the other hand the socio economic status, cultural beliefs, perceptions, knowledge, systems, health infrastructure, etc. have been influencing it from various dimensions. The ecological factors also influence the nutrition pattern, dietary behavior of the community, which is different from one geo-ecological zone to other. Orissa, one of the backward states of India, has a heterogeneous ethnic composition with 62 tribes and 93 scheduled caste communities, which constitute $22.2 \%$ and $16.2 \%$ of the total population respectively (Government of Orissa, 2000). These communities are techno-economically backward and trailing in all spheres of life. Health status in general and antenatal care in particular is not out of it. Realizing the importance among these vulnerable communities, the government of India has accepted the national program, Integrated Child Development Schemes (ICDS). The package of services includes physical and obstetrical examination: monitoring weight, blood pressure, supplying iron and folic acid tablets, food supplements, identification and referral of high-risk mothers and health education on antenatal care, breast-feeding, child rearing and family planning (Yagnik, 1994).

Adak (1997) did research work on mortality relation with some biosocial proximities like education/occupation of mothers, place of delivery and drinking water used at household level on tribal population of Shillong. It had been observed that among all these population (Garo, 
Mizo and Khasi) almost all the couples were literate except in Khasi 1/10 of husband and1/5 of wives were illiterate and most of the literate had either primary or high school level of education. Pandey and Goel (1999) studied on the demographic characteristics of Abujhmaria tribe of Bastar district in Madhaya Pradesh. The findings showed that majority of population were poor and illiterate. The fertility and mortality rate were high. Acceptance of family planning was nil. Nayak and Babu (2001) studied on the utilization of services for safe motherhood, antenatal care (ANC), among the schedule caste (SC) and schedule tribes (ST) of Orissa. It was found that ANC services were much poorer in case of SC and ST as compared to general population. Also various socio-economic and cultural factors were influencing the acceptance of ANC among these vulnerable communities.

\section{MATERIALS AND METHODS}

The present study has been conducted in thirty-five villages from all the seven blocks (Mawphlang, Mawryngkneng, Mylliem, Mawkynrew, Mawsynram, Shella and Pynursla) of East Khasi Hill district of Meghalaya. The data collection was on the various health aspects related to antenatal care received by the women in the community, the infrastructure available and the role of different government and private institutions in providing ANC facilities to the population covered in the study. The field survey involved collection of the data and information in the structured interview schedules Besides quantitative data through interview schedules, qualitative data was also collected through FGDs conducted at the grass root to know various myths and misconceptions in the community.

\section{RESULTS}

It was found that around 82 percent women of East Khasi hills received antenatal checkups during pregnancy, whereas, in Meghalaya 54 percent women had received ANC according to NFHS -2 (1998-1999). In this state there has been a slight decline between the two surveys in the proportions of births for which women received an ANC (from 56 percent inNFHS-1 to 54 percent in NFHS -2). Table 1 shows that Shella and Mawsynram blocks women received antenatal check-ups for 91 percent of births, 85.3 percent for Mawphlang, 82.9 percent for Mylliem, 80 percent for Mawryngkneng, 78.percent for Mawkynrew and 76.1 percent for Pynursla

Table 1: Percentage distribution of antenatal checkup received by the women of East Khasi Hills

\begin{tabular}{|c|c|c|c|c|}
\hline \multirow[t]{2}{*}{ Block } & \multicolumn{2}{|c|}{ Received ANC } & \multicolumn{2}{|c|}{ Did not receive $A N C$} \\
\hline & Freq. & $\%$ & Freq. & $\%$ \\
\hline Mawphlang & 87 & 85.3 & 15 & 14.7 \\
\hline Mawryngkneng & 364 & 80.0 & 91 & 20.0 \\
\hline Mylliem & 382 & 82.9 & 79 & 17.1 \\
\hline Mawkynrew & 160 & 78.4 & 44 & 21.6 \\
\hline Mawsynram & 93 & 91.2 & 9 & 8.8 \\
\hline Shella & 140 & 91.5 & 13 & 8.5 \\
\hline Pynursla & 232 & 76.1 & 73 & 23.9 \\
\hline Total & 1458 & 81.8 & 324 & 18.2 \\
\hline
\end{tabular}

More than 95 percent received antenatal checkups from doctor MBBS doctors, 4.3 percent went to antenatal midwife (ANM) or staff nurse. A small proportion (0.3) percent received antenatal checkups from traditional birth attendants in all the blocks. Chi-square test was applied to test whether there was any location impact in ANC check-up. The calculated value was found to be 81.0 and D.F. 36, which showed that it is statistically significant at $5 \%$ probability level. (Table 2). In comparison with NFHS-2 data, in Meghalaya 47.3 percent received their ANC from doctors, 4.2 from other health professionals and 0.5 from local traditional practitioner.

Table 2: Consultation taken for antenatal checkups

\begin{tabular}{lrcc}
\hline Block & Doctors & $\begin{array}{c}\text { ANM/Staff- } \\
\text { Nurse/LHV }\end{array}$ & $\begin{array}{c}\text { Traditional } \\
\text { Doctor/ } \\
\text { Untrained } \\
\text { Dia/Others }\end{array}$ \\
\hline Mawphlang & 97.7 & 0 & 2.3 \\
Mawrygkneng & 93.7 & 6.0 & 0.3 \\
Mylliem & 97.4 & 2.6 & 0 \\
Mawkynrew & 84.4 & 15.6 & 0 \\
Mawsyram & 98.6 & 1.4 & 0 \\
Shella & 100.0 & 0 & 0 \\
Pynursla & 97.4 & 1.7 & 0.9 \\
\hline Total & 95.3 & 4.3 & 0.3 \\
\hline
\end{tabular}

Table 3 shows that 21.7 percent of the women received their full ANC, i.e, antenatal check-up from the first month of their pregnancy, whereas, according to DLHS-2 (2002-2004) only 9.7 percent women received their full ANC and 11.7 percent women in Meghalaya. 17.5 percent went for their first ANC in the second month, 13.2 percent in the third month, 14.7 percent in the fourth month 
Table 3: Percentage distribution of the first antenatal checkup

\begin{tabular}{|c|c|c|c|c|c|c|}
\hline \multirow[t]{2}{*}{ Block } & \multicolumn{5}{|c|}{ Months } & \multirow{2}{*}{$\begin{array}{c}\text { Did not } \\
\text { reme- } \\
\text { mber } \\
\end{array}$} \\
\hline & $1 s t$ & $2 n d$ & $3 r d$ & $4 t h$ & $5 t h$ & \\
\hline Mawphlang & 31.0 & 12.6 & 17.2 & 12.6 & 25.3 & 1.1 \\
\hline Mawryngkneng & 18.4 & 18.4 & 9.3 & 15.9 & 35.7 & 2.2 \\
\hline Mylliem & 19.9 & 18.3 & 11.8 & 14.1 & 33.8 & 2.1 \\
\hline Mawkynrew & 21.9 & 16.9 & 15.6 & 9.4 & 33.1 & 3.1 \\
\hline Mawsynram & 21.5 & 31.2 & 11.8 & 17.2 & 17.2 & 1.1 \\
\hline Shella & 14.3 & 17.1 & 13.6 & 25.7 & 23.6 & 5.7 \\
\hline Pynursla & 30.6 & 11.6 & 18.5 & 10.8 & 28.0 & 0.4 \\
\hline Total & 21.7 & 17.5 & 13.2 & 14.7 & 30.7 & 2.2 \\
\hline
\end{tabular}

and 30.7 percent received first ANC between fifth and ninth month of their pregnancy and 2.2 percent could not remember when they went for their first antenatal check-up.

It was reported in the Focus Group Discussion (FGD) that many women could not go for antenatal check-ups as there were no such facilities in the village they either had to go to the nearest village or to the district hospital private hospital at Shillong, the district headquarter.

The most common components of antenatal check-ups found in these blocks were abdominal examination, blood pressure, weight and TTinjection. Overall in all the blocks, 79 percent women had their blood pressure measured, 80 percent had an abdominal examination, weight was measured in 78 percent of cases, 77 percent received their TT injection, 51 percent reported having had a blood test and 41 percent had a urine test.
Table 4 shows the percentage distribution of the number of times tetanus toxoid injection (TT) and iron and folic acid (IFA) tablets or syrup received by the mothers during pregnancy. It was found that 83.3 percent women received TT injection twice and 16.7 percent received only once. Majority of the women who received TT injection twice were from Mawplang (94.5 percent) and the least number of women for receiving this injection were from Pynursla (76 percent), of the total women who received 16.3 percent of the women received just one TT injection, 24 percent were from Pynursla. 16.8 percent were from Mylliem and 5.5 percent were in Mawphlang. Moreover, 79.8 percent have received IFA Tablets and 79.3 percent have consumed them all. The maximum number of women (86.9 percent) was from Shella block that have received IFA Tablets and 86.3 percent have consumed them all (Table 4). According to Reproductive and Child Health, DLHS (20022004) and Facility Survey 2003, in East Khasi hills 69.9 percent women received TT injection only once and 12.1 percent received IFA tablets.

Women who gave birth to a child, 45 per cent delivered in their in-laws house, 1 percent in their parents' house and a very negligible percentage ( 0.6 percent) had their delivery in any other house. Table 5 shows that women belonging to Mawkynrew block had maximum deliveries in their in-laws home, followed by Pynursla, Mawsynram and Mawryngkneng. The main reason for home delivery is the distance from the

Table 4: Percentage distribution of number of times TT injection and IFA tablets received and consumed

\begin{tabular}{|c|c|c|c|c|c|c|c|c|}
\hline $\begin{array}{c}\text { Types of ANC } \\
\text { check-up }\end{array}$ & $\begin{array}{c}\text { Maw- } \\
\text { phlang }\end{array}$ & $\begin{array}{l}\text { Mawryng- } \\
\text { kneng }\end{array}$ & Mylliem & $\begin{array}{l}\text { Mawkyn- } \\
\text { rew }\end{array}$ & $\begin{array}{l}\text { Mawsyn- } \\
\text { ram }\end{array}$ & Shella & Pynursla & Total \\
\hline \multicolumn{9}{|c|}{ Number of Times TT Injection Received } \\
\hline Once & 5.5 & 15.1 & 16.8 & 15.9 & 11.2 & 15.1 & 24.1 & 16.7 \\
\hline Twice & 94.5 & 85.0 & 83.2 & 84.0 & 88.7 & 85.0 & 75.9 & 83.3 \\
\hline \multicolumn{9}{|c|}{ IFA Tablets Received and Consumed } \\
\hline IFA Tablets received & 81.4 & 78.7 & 80.3 & 76.5 & 91.2 & 86.9 & 75.1 & 79.8 \\
\hline IFA tablets consumed & 80.4 & 77.8 & 80.0 & 76.0 & 91.2 & 86.3 & 75.1 & 79.3 \\
\hline
\end{tabular}

Table 5: Block-wise places where women gave birth to a child

\begin{tabular}{lccccccc}
\hline Block & $\begin{array}{c}\text { District } \\
\text { Hospital }\end{array}$ & $\begin{array}{c}\text { CHC/Rural } \\
\text { Hospital }\end{array}$ & PHC & $\begin{array}{c}\text { Private Hospital/ } \\
\text { Nursing Home }\end{array}$ & $\begin{array}{c}\text { In-laws } \\
\text { home }\end{array}$ & $\begin{array}{c}\text { Parent's } \\
\text { home }\end{array}$ & $\begin{array}{c}\text { Other } \\
\text { home }\end{array}$ \\
\hline Mawphlang & 43.5 & 0.0 & 0.0 & 18.5 & 26.1 & 5.4 & 6.5 \\
Mawryngkneng & 26.8 & 1.6 & 0.9 & 22.4 & 45.9 & 2.1 & 0.2 \\
Mylliem & 35.0 & 0.9 & 0.0 & 30.2 & 33.4 & 0.2 & 0.2 \\
Mawkynrew & 11.7 & 0.0 & 0.5 & 23.4 & 62.4 & 1.0 & 1.0 \\
Mawsynram & 34.0 & 0.0 & 0.0 & 13.4 & 52.6 & 0.0 & 0.0 \\
Shella & 26.9 & 9.7 & 1.4 & 23.4 & 37.9 & 0.7 & 0.0 \\
Pynursla & 21.1 & 0.4 & 0.4 & 21.1 & 57.2 & 0.0 & 0.0 \\
\hline Total & 27.5 & 1.5 & 0.5 & 23.7 & 45.1 & 1.1 & 0.6 \\
\hline
\end{tabular}


Table 6: Block-wise outcome of the pregnancy

\begin{tabular}{|c|c|c|c|c|c|}
\hline Block & Live birth & Still birth & $\begin{array}{c}\text { Died immediately } \\
\text { after birth }\end{array}$ & $\begin{array}{l}\text { Could not } \\
\text { survive }\end{array}$ & $\begin{array}{l}\text { Presently } \\
\text { pregnant }\end{array}$ \\
\hline Mawphlang & 78.4 & 2.1 & 2.1 & 11.3 & 6.2 \\
\hline Mawryngkneng & 89.5 & 1.1 & 1.6 & 6.2 & 1.6 \\
\hline Mylliem & 90.4 & 1.3 & 1.6 & 4.9 & 1.8 \\
\hline Mawkynrew & 93.5 & 1.0 & 1.5 & 3.5 & 0.5 \\
\hline Mawsynram & 96.0 & 1.0 & 1.0 & 1.0 & 1.0 \\
\hline Shella & 84.3 & 2.6 & 3.3 & 5.2 & 4.6 \\
\hline Pynursla & 86.0 & 2.7 & 3.0 & 5.0 & 3.3 \\
\hline Total & 88.9 & 1.6 & 2.0 & 5.2 & 2.3 \\
\hline
\end{tabular}

health centers and the non-availability of other facilities like transport, cost involved etc. 27.5 percent had their delivery in the district hospitals and 23 percent in the private hospitals/nursing homes. It was found that traditional delivery plays a substantial role in East Khasi Hills, 22.5 percent went to the traditional birth attendants and trained birth attendants attended 19 percent. The nurse assisted 15.3 percent of the women in their last delivery whereas, 33.6 per cent women took assistance from doctor (MBBS and above). The proportions of institutional births in Meghalaya have declined from 31 percent in NFHS-1 to 17 percent in NFHS-2. Whereas in all other states in North East India the proportion of institutional births has increased since NFHS1 to NFHS- 2 except the state of study and Nagaland. According to DLHS-RCH, 2002-2004 in East Khasi Hills 73.3 percent women had institutional delivery, while in the present study only 52.3 percent women had institutional delivery. The reasons for more home deliveries were the absence of delivery facilities in the nearest $\mathrm{CHCs}$ and PHCs (FGD).

Almost 89 percent had successful delivery only 2 percent cases were reported where the babies died immediately after birth and some of them who could not survive later were 5.2 percent (Table 6). It was reported in FGD that improper facilities and care provided by the government hospitals had at times led to the death of the baby. There had been cases when the child died of cold and other infections due to carelessness of the hospital staff. Cases of mother and child death during childbirth occurred but such cases were rare.

\section{DISCUSSION}

The observation made under the present study clearly indicate that the women receiving antenatal checkups, source of antenatal checkups, percentage distribution of first antenatal checkups and place of delivery has been much influenced by location. When chisquare test was applied to test whether there was any location impact in ANC check-up it was found to be statistically significant at $5 \%$ probability level.

The percentage of births attended by untrained personnel also played a major role regarding few of the infant or child death in the district; it was also noted by Nayak and Babu (2001). This may be attributed to the fact that proper use of Health and Family Welfare programme can reduce these mortalities. Most of the women received ANC in the third trimester. These wide disparities in ANC may be due to certain Socio-economic variables like low level of education and lower economic condition.

From the above facts it is also tangible that most women failed to receive full ANC because they did not register early enough. According to NFHS III in Meghalaya, the state of the present study, the health and family welfare programme had much scope for improvement, as antenatal care was not availed by the women in about 48 percent cases of live births. The percentage was as high as about 57 in the rural areas and as high as about 74 among illiterate women. Therefore, it is suggested that whenever women conceive they should register themselves in a hospital. Once the pregnant women are identified, the ANM should be directed to visit these women and provide them quality health care services for which suitable guidelines should be prepared.

\section{ACKNOWLEDGEMENT}

Sincere thanks and gratitude to Dr. Ashok K. Chauhan (Founder President of Amity Institutions) Prof. Ashish Bose (Honorary 
Professor, Institute of Economic Growth, University of Delhi), Dr. Sunil Saran (Former Director), Prof. A.K. Srivastava (Director) Amity Institute of Biotechnology, Prof. A.K. Kalla (Deptartment of Anthropology, University of Delhi, Delhi) for their constant guidance and encouragement. The author acknowledges deep sense of gratitude to Debashish Deb for his constant support. Gratefully acknowledge the financial support received from Ministry of Health and Family Welfare, Government of India for conducting the present research project.

\section{REFERENCES}

Adak, D.K. 1997. "Mortality in Relation to Some Biosocial Proximity: A Study on Tribal Population of Shillong. (Meghalaya)." South Asian Anthropologists, 18(2): 113-121

Bourne, B. 1972. Pregnancy, London: Cassell and Company Ltd.

Chandrasekhar, S., R. S. Rao, N. S. Nair and Kutty, P.R. 1998. "Socio-Demographic Determinants of Antennal care." Tropical Doctors, 28: 206-209

DLHS-2, 2002-04. Reproductive and Child Health, District Level Household Survey. Mumbai: International Institute of Population Sciences.

Government of Orissa 2000. Economic Survey 19992000. Cuttack: Government Press

India Summary Report, Reproductive and Child Health.
District Level Household Survey (2002-2004) \& Facility Survey 2003. Mumbai: International Institute of Population Science.

Malher, H. 1987. "The Safe Motherhood Initiative: A Call to Action." Lancet, 1: 268-270

Nair, N.S., R.S Rao, S. Chandrasekhar, D. Archarya, and H. V. Bhat, 2000. "Socio Demographic and Maternal Determinants of Low Birth Weights: A Multivariate Approach." Indian Journal of Pediatrics, 67: 9-14.

Nayak, A.N. and B.V. Babu 2001." Utilization of Services Related to Safe Motherhood among the Schedule Caste and Schedule Tribe population of Orrissa: An Overview." South Asian Anthropologists. 20 (2): $85-88$

NFHS-1, 1993-94. Northerneastern States, National Family Health Survey India. Bombay: International Institute of Population Sciences.

NFHS-2, 1998-99. Northerneastern States, National Family Health Survey India. Mumbai: International Institute of Population Sciences.

NFHS-3, 2003-04. Northerneastern States, National Family Health Survey India. Mumbai: International Institute of Population Sciences.

Pandey, G.D. and A.K.Goel 1999. "Socio- Demographic Characteristics of Abujhmaria Madhaya Pradesh." South Asian Anthropologists, 20 (2): 85-88

Park, J.E. and K. Park, 1991. Textbook of Preventive and Social Medicine. Jabalpur: Banarasidas Bhanot Publishers.

Yagnik, N D. 1930. Health development of mothers through systems of ICDS. India Journal of Maternal and Child Health, 4(1): 11-15 